\title{
The interactions of age, genetics, and disease severity on tacrolimus dosing requirements after pediatric kidney and liver transplantation
}

\author{
Saskia N. de Wildt • Ron H. N. van Schaik • Offie P. Soldin • Steve J. Soldin • \\ Parvaneh Yazdani Brojeni • Ilse P. van der Heiden • Chris Parshuram • \\ Irena Nulman • Gideon Koren
}

Received: 13 April 2011 / Accepted: 6 June 2011 / Published online: 23 June 2011

(C) The Author(s) 2011. This article is published with open access at Springerlink.com

\begin{abstract}
Purpose In children, data on the combined impact of age, genotype, and disease severity on tacrolimus (TAC) disposition are scarce. The aim of this study was to evaluate the effect of these covariates on tacrolimus dose requirements in the immediate post-transplant period in pediatric kidney and liver recipients.

Methods Data were retrospectively collected describing tacrolimus disposition, age, $C Y P 3 A 5$ and $A B C B 1$ genotype, and pediatric risk of mortality (PRISM) scores for up to 14 days post-transplant in children receiving liver and renal transplants. Initial TAC dosing was equal in all patients and adjusted using therapeutic drug monitoring. We determined the relationship between covariates and tacrolimus disposition. Results Forty-eight kidney and 42 liver transplant recipients (median ages 11.5 and 1.5 years, ranges $1.5-17.7$ and $0.05-$ 14.8 years, respectively) received TAC post-transplant. In both
\end{abstract}

\section{P. Y. Brojeni · I. Nulman • G. Koren}

Division of Clinical Pharmacology and Toxicology,

The Hospital for Sick Children,

Toronto, ON, Canada

S. N. de Wildt $(\square)$

Intensive Care and Department of Pediatric Surgery,

Erasmus MC Sophia Children's Hospital,

Sk3140, Dr. Molewaterplein 60,

3015 GJ, Rotterdam, The Netherlands

e-mail: s.dewildt@erasmusmc.nl

R. H. N. van Schaik • I. P. van der Heiden

Pharmacogenomics Core Laboratory,

Department of Clinical Chemistry, Erasmus MC,

Rotterdam, The Netherlands

O. P. Soldin $\cdot$ S. J. Soldin

Departments of Oncology, Medicine, Physiology and Biophysics,

Georgetown University Medical Center,

Washington, DC, USA transplant groups, younger children ( $<5$ years) needed higher TAC doses than older children [kidney: 0.15 (0.07-0.35) vs. $0.09(0.02-0.20) \mathrm{mg} / \mathrm{kg} / 12 \mathrm{~h}, p=0.046$, liver: $0.12(0.04$ $0.32)$ vs. $0.09(0.01-0.18) \mathrm{mg} / \mathrm{kg} / 12 \mathrm{~h}, p=0.038]$. In kidney but not liver transplants, CYP3A5 expressors needed significantly higher TAC doses than nonexpressors $[0.15$ (0.07-0.20) vs. $0.09(0.02-0.35) \mathrm{mg} / \mathrm{kg} / 12 \mathrm{~h}, P=0.001]$. In these patients, age and CYP3A5 genotype were independently associated with TAC dosing requirement. In liver, but not kidney transplant patients, homozygous ABCB1 T-T-T haplotype carriers needed higher TAC doses than noncarriers [0.26 (0.15-0.32) vs. $0.11(0.01-0.25) \mathrm{mg} / \mathrm{kg} / 12 \mathrm{~h}, p=0.013]$. Conclusion CYP3A5 genotype may explain variation in tacrolimus disposition early after transplant in pediatric kidney recipients, independent of age-related variation. In contrast, in pediatric liver recipients, variation in tacrolimus disposition appears related to age and $A B C B 1$ genotype. These

\section{G. Koren}

Ivey Chair in Molecular Toxicology,

Department of Medicine,

University of Western Ontario,

London, ON, Canada

\author{
C. Parshuram \\ Department of Critical Care Medicine, \\ Hospital for Sick Children, \\ Toronto, ON, Canada
}

I. Nulman

Child Health Evaluative Sciences,

The Research Institute,

Hospital for Sick Children,

Toronto, ON, Canada 
findings illustrate the importance of the interplay among age, genotype, and transplant organ on tacrolimus disposition.

Keywords Tacrolimus $\cdot$ Liver transplant $\cdot$ Kidney transplant $\cdot$ CYP3A5 $\cdot A B C B 1 \cdot$ Pharmacokinetics $\cdot$ Pediatrics

\section{Introduction}

Tacrolimus is a potent immunosuppressive drug, used in most pediatric solid organ transplant recipients to prevent transplant rejection. This drug is characterized by a narrow therapeutic window and high inter- and intraindividual variability in disposition [1]. Drug concentrations can show up to 100 -fold variation in individual patients. Transplant rejection rates as well as most of the adverse events associated with tacrolimus (including nephrotoxicity, neurotoxicity, hypertension, infections, and lymphoproliferative disease) may be, at least partially, concentration-related [2]. These serious adverse events associated with tacrolimus therapy provide a compelling rationale for the use of rigorous therapeutic drug monitoring. This is especially true because, with a tacrolimus half-life of up to $40 \mathrm{~h}$, it may take $3-5$ days before a tacrolimus dosing adjustment results in a new, adequate blood concentration [2]. All this time the patient may be at an increased risk for transplant rejection or adverse events.

Tacrolimus pharmacokinetics has been extensively investigated in adults. However, data in children are more limited [3]. Young children (1-6 years of age) appear to need higher doses per kilogram body weight of tacrolimus than older children and adults to maintain similar trough concentrations. The reason for this age-related faster clearance rate is unknown.

In addition to age-related differences in tacrolimus pharmacokinetics, large inter- and intraindividual variation is observed due to other factors. For example, genetic variation in CYP $3 A 5$ has been shown to explain a large part of the variation in tacrolimus disposition in both adult and small cohorts of pediatric solid organ transplant patients, as recently reviewed by Quteineh et al. [4-12]. The impact of genetic variation in $A B C B 1$ gene activity on tacrolimus disposition remains controversial to date [13].

The impact of age and genetic variation appears to be weakened in the immediate post-transplantation period, while intraindividual variation appears larger [14]. This finding may be explained by other factors affecting tacrolimus disposition postoperatively. For example, CYP3A activity appears to be downregulated by proinflammatory factors, mainly TNF $\alpha$, IL-1, and IL-6, which may be released after organ transplant surgery [15]. Yet, data regarding the effect of inflammation or disease severity on tacrolimus disposition in the immediate post-transplant period are lacking.
While limited data on the effect of age and CYP $3 A 5$ genotype on tacrolimus pharmacokinetics in children exist, the interplay of age, CYP $3 A 5$ genotype, and disease severity in relation to tacrolimus pharmacokinetics in pediatric solid transplant patients has not been elucidated, especially not in the immediate post-transplant period, when variation appears to be largest. This is important, as age-related changes in pharmacokinetics may obscure genetic variation. Similarly, inflammation and/or organ failure may reduce drug metabolism in patients who would otherwise have tacrolimus clearance comparable to adults or even faster. Due to this lack of data on the interplay of these possible covariates, the pediatric transplant patient is subjected to a higher risk of adverse events or transplant rejection.

The aim of this study was therefore to retrospectively determine the combined effect of age, CYP $3 A 5$ and $A B C B 1$ genotype, and disease severity on tacrolimus dosing requirements and disposition in a cohort of pediatric liver and kidney recipients in the 2 weeks following transplantation. These two patient groups differ in that, in the liver transplant patients, recipient $C Y P 3 A 5$ and $A B C B 1$ genotype may only affect intestinal $C Y P 3 A 5$ and $A B C B 1$ activity, whereas in the kidney transplant patients, $C Y P 3 A 5 / A B C B 1$ genotype may affect both intestinal and liver $C Y P 3 A 5 /$ $A B C B 1$ activity.

\section{Methods and materials}

Study design

Retrospective cohort study in pediatric liver and kidney transplant patients who received tacrolimus in the first 14 days after transplant.

\section{Patient population}

Patients were eligible for study entry if they were $0-18$ years of age at the time of liver or kidney transplant and received tacrolimus during the first 14 days posttransplant between 2000 and 2008 at the Hospital for Sick Children, Toronto, Ontario. From December 2006 to March 2008, all patients who visited the Outpatient Transplant Clinic or who were admitted to the hospital for transplant or follow-up were approached for informed consent. Transferred patients (out of the SickKids program) or deceased patients were not included. For deceased patients no DNA was available. The study was approved by the Hospital for Sick Children's Research Ethics Board. Informed consent and, if applicable, children's assent were obtained from all parents/legal representatives and/or patients. 
Immunosuppression protocol

All patients were started by the transplant physician on SickKid's transplant immunosuppression protocol therapy consisting of methylprednisolone, mycophenolate mofetil, and tacrolimus. A minority of patients received basiliximab or thymoglobulin (Table 1). Methylprednisolone $(10 \mathrm{mg} / \mathrm{kg})$ was intravenously administered at the time of graft reperfusion and gradually tapered after transplant (Table 1). Tacrolimus starting dose was 0.1 $\mathrm{mg} / \mathrm{kg}$ orally twice daily in all patients and was subsequently adjusted by routine pre-dose tacrolimus concentrations to reach the preset target tacrolimus $\mathrm{C}_{0}$ concentration of $10-15 \mathrm{ng} / \mathrm{ml}$ for both groups. No predefined dose adaptation algorithm was used. Doses were adapted by the transplant physician in collaboration with the hospital pharmacist.

\section{Clinical data collection}

The following patient characteristics were collected from SickKids electronic patient databases: transplant type, age at transplant, sex, weight, PRISM III score, duration of mechanical ventilation and ICU stay, chemical and hematological test results, and relevant co-medication (CYP3A5/ABCB1 inducers/inhibitors). Initial liver graft failure was defined as ASAT and/or ALAT >1,500 IU/1 in the first $72 \mathrm{~h}$ after transplant, as defined by Nanashima et al. [16].
The following information was collected on tacrolimus: doses (date/time) and tacrolimus morning pre-dose blood concentrations (date/time).

The PRISM III score is a widely used and validated score in the pediatric intensive care setting assessing the severity of illness and the potential risk of mortality in critically ill children [17]. The PRISM is based on 14 routinely measured clinical and laboratory parameters with age-normalized normal ranges [17].

Outcome measures

The primary outcome measure was median tacrolimus dosing requirement (normalized for body weight). Secondary outcome measures were median tacrolimus concentrations and concentration/dose ratio (normalized for body weight), as surrogate marker for tacrolimus clearance.

Independent variables

Independent variables included recipient age, $C Y P 3 A 5$ and $A B C B 1$ genotype, and PRISM score.

\section{DNA collection}

For DNA analysis, blood for DNA $(0.5 \mathrm{ml})$ was collected during regular blood work at the Transplant Outpatient Clinic. In cases where DNA collection from blood was not possible, saliva was collected using the Oragene TM DNA

Table 1 Characteristics of the 90 pediatric liver and kidney transplant recipients

\begin{tabular}{|c|c|c|c|c|c|c|c|}
\hline & \multicolumn{3}{|l|}{ Kidney } & \multicolumn{3}{|l|}{ Liver } & \multirow[t]{2}{*}{$P$-value } \\
\hline & Number & Median & Range & Number & Median & Range & \\
\hline Male/female & $29 / 19$ & & & & & & 0.39 \\
\hline Weight $(\mathrm{kg})$ & 48 & 33.7 & $10.7-80$ & 42 & 10.9 & $2.6-64$ & $<0.000$ \\
\hline Age (years) & 48 & 11.5 & $1.5-17.7$ & 42 & 1.5 & $0.05-14.8$ & $<0.000$ \\
\hline PRISM & 40 & 7 & $2-16$ & 30 & 7.5 & $0-28$ & 0.497 \\
\hline Days in ICU & 48 & 2 & $1-14$ & 42 & 6 & $2-14$ & $<0.000$ \\
\hline Days on ventilator & 48 & & $0-4$ & 42 & 1 & $0-12$ & $<0.000$ \\
\hline Mean airway pressure $\left(\mathrm{cm} \mathrm{H}_{2} \mathrm{O}\right)$ & 3 & 13 & $11-14$ & 31 & 11 & $8-18$ & 0.214 \\
\hline Urinary output (mL/kg/u) & 42 & 5.0 & $1.5-30.4$ & 42 & 3 & $0.8-5.9$ & $<0.000$ \\
\hline Creatinin $(\mu \mathrm{mol} / \mathrm{L})$ & 48 & 87.0 & $19-415$ & 42 & 26.3 & $14-138$ & 0.000 \\
\hline Albumin $(\mathrm{g} / \mathrm{L})$ & 48 & 31.3 & $26.7-37$ & 42 & 31.0 & $20-37$ & 0.255 \\
\hline Hematocrit (L/L) & 48 & 0.3 & $0.23-0.48$ & 42 & 0.3 & $0.25-0.45$ & 0.017 \\
\hline \multicolumn{8}{|l|}{ Methylprednisolone dose } \\
\hline Day 1 (mg/kg/day) & 48 & 2 & $0.7-3$ & 42 & 3.9 & $1.8-4$ & \\
\hline Day 7 (mg/kg/day) & 48 & 1.6 & $1.5-1.8$ & 42 & 0.3 & $0.1-0.3$ & \\
\hline Day 14 (mg/kg/day) & 48 & 1.2 & $1.0-1.5$ & 42 & 0.28 & $0.05-0.3$ & \\
\hline Basiliximab (yes/no) & $0 / 48$ & & & $6 / 36$ & & & \\
\hline Thymoglobulin (yes/no) & $2 / 46$ & & & $4 / 38$ & & & \\
\hline
\end{tabular}


self-collection kit following the manufacturer's instructions (DNA Genotek, Kanata, ON).

\section{Laboratory analysis}

Tacrolimus concentrations Tacrolimus blood concentrations were determined in EDTA whole blood $(0.25 \mathrm{ml})$, using LCMS-MS as described previously [18].

Genotyping Genomic DNA was isolated from $0.2 \mathrm{ml}$ ethylenediaminetetraacetic acid-treated whole blood using a MagnaPure LC (Roche Diagnostics, Mannheim, Germany). Genotyping was done using Taqman allelic discrimination assays on the API Prism 7900 HT sequence detection system (Applied Biosystems, CA, USA) on 1 ng of genomic DNA, as previously reported $[19,20]$. Patients not carrying the $C Y P 3 A 5^{*} 3$ allele were assigned the $C Y P 3 A 5^{*} 1 * 1$ genotype by default. For the allelic variant G2677A/T, two separate assays were designed, one detecting G2677T, one detecting G2677A.

\section{Statistical analyses}

Data are presented as mean $\pm \mathrm{SD}$ or median (range) when the data were not normally distributed.

$C Y P 3 A 5$ and $A B C B 1$ genotypes were tested for HardyWeinberg equilibrium. For the results, we compared mean differences using $t$-test or the rank-sum test when the data were not normally distributed. As the $A B C B 1$ polymorphisms are expected to be in linkage disequilibrium, multiple testing does not apply to the three different genotypes and one haplotype [21]. For comparison of categorical variables, chi-squared or Fisher's exact test was used, as appropriate. We studied correlations using Spearman's correlation test. With an expected cohort of 100 patients to be included (50 liver, 50 kidney), we a priori restricted our analysis to a maximum of four variables (age, $C Y P 3 A 5$ and $A B C B 1$ genotype, and PRISM score), based on the general rule of thumb for multiple regression analysis that $10-20$ patients are needed per variable.

To test the relative contribution and interaction of significant covariates from univariate analysis, multivariate analysis was performed using a general linear model. Data analysis was performed using SPPS statistical software (SPSS 16.0, Chicago, IL)

\section{Results}

Patient inclusion and clinical characteristics

The total transplanted patient cohort at the Hospital for Sick Children transplant unit as of February 2008 was 124 kidney and 91 liver transplant patients. Of these patients, approximately $80 \%$ received tacrolimus in the first 2 weeks of transplant. All patients who received tacrolimus in the first 2 weeks after transplant were approached for informed consent when they visited the SickKids Transplant Outpatient clinic between November 2006 and February 2008. In addition, all patients who received a new transplant during this period were asked for informed consent. Informed consent rate was $>95 \%$. Patients that were missed were patients that moved out of the Toronto area or that were transferred to the adult transplant clinic for follow-up. In addition, patients that passed away could not be included, as we could not obtain DNA from these patients.

Between December 2006 and March 2008, 42 pediatric liver recipients and 48 kidney recipients were enrolled (Table 1). The liver recipients were much younger than the kidney recipients [median (range)]: 1.5 years $(0.05-14.8)$ and 11.5 years $(1.5-17.7), p<0.001$, respectively. Median durations of mechanical ventilation and stay at the ICU were longer in the liver than in the kidney patients (Table 1).

Tacrolimus dosing requirements and disposition

Median tacrolimus doses were similar in both transplant groups, with large interindividual variation in tacrolimus doses over the first 14 days post-transplant: $0.1 \mathrm{mg} / \mathrm{kg}$ (range 0.01-0.35, IQR 0.08-0.15) for kidney and $0.1 \mathrm{mg} /$ $\mathrm{kg}$ (range 0.01-0.31, IQR 0.08-0.16) for liver recipients (Table 2). On average 9 tacrolimus concentrations (range 412) per patient were available for the first 14 days posttransplant. Median concentration/dose ratios (as surrogate measure of clearance rate) also showed large interindividual variation: 78 (range 25-280, IQR 45-108) ng/ml*mg/kg/ $12 \mathrm{~h}$ for kidney and $87 \mathrm{ng} / \mathrm{ml} * \mathrm{mg} / \mathrm{kg} / 12 \mathrm{~h}$ (range $25-280$, IQR 58-139) for liver recipients.

Less than $40 \%$ of all tacrolimus concentrations were in the predefined therapeutic target range $(10-15 \mathrm{ng} / \mathrm{ml})$, as shown in Fig. 1. In the kidney recipients, more than $50 \%$ of all concentrations were below the therapeutic target range. In the liver recipients, $33 \%$ of concentrations were below and $25 \%$ of all concentrations above this range. In this group, very high concentrations were observed.

Effect of $C Y P 3 A 5$ and $A B C B 1$ genotype on tacrolimus dosing and concentrations

DNA for both $C Y P 3 A 5$ and $A B C B 1$ genotyping was available for 39 kidney and 32 liver recipients. Missing results were due to limitations in sample collection logistics and DNA analysis. The genotyped and nongenotyped groups did not differ in age, gender, weight, or tacrolimus exposure. DNA for CYP3A5 genotyping was available for 
Table 2 Tacrolimus (tac) dosing characteristics of the 90 subjects by transplant type

\begin{tabular}{|c|c|c|c|c|c|c|c|}
\hline & \multicolumn{3}{|l|}{ Kidney } & \multicolumn{4}{|l|}{ Liver } \\
\hline & Number & Median & Range & Number & Median & Range & $P$-value \\
\hline Tac samples per patient & 48 & 9 & $2-11$ & 42 & 9 & $5-12$ & 0.221 \\
\hline Median tac trough level $(\mathrm{ng} / \mathrm{mL})$ & 48 & 9 & $2.8-15.5$ & 42 & 11.5 & $5-15$ & 0.000 \\
\hline Median tac dose $(\mathrm{mg} / \mathrm{kg})$ & 48 & 0.1 & $0.02-0.35$ & 42 & 0.1 & $0.01-0.32$ & 0.389 \\
\hline Conc/dose (ng/ml per mg/kg) & 48 & 78 & $25-280$ & 42 & 87 & $25-1,939$ & 0.162 \\
\hline Tac concentrations $<5 \mathrm{ng} / \mathrm{mL}$ & 48 & 5 & $0-11$ & 42 & 3 & $0-9$ & 0.003 \\
\hline Tac concentrations $10-15 \mathrm{ng} / \mathrm{mL}$ & 48 & 2 & $0-9$ & 42 & 3 & $0-7$ & 0.033 \\
\hline Tac concentrations $>15 \mathrm{ng} / \mathrm{mL}$ & 48 & 0 & $0-3$ & 42 & 2 & $0-5$ & 0.000 \\
\hline Upward dose changes & 48 & 4 & $0-8$ & 42 & 4 & $1-8$ & 0.889 \\
\hline Downward dose changes & 48 & 2 & $0-5$ & 42 & 3 & $0-5$ & 0.010 \\
\hline
\end{tabular}

44 of 48 kidney recipients and for 35 of 42 liver recipients. Genotype distribution for kidney recipients was $n=1,15$, and 28 , respectively, for $C Y P 3 A 5^{*} 1 / * 1, * 1 / * 3$, and $* 3 / * 3$. Similarly, distribution in liver recipients was $n=1,12$, and 22. Genotype distribution was in Hardy-Weinberg equilibrium for both groups ( $p=0.53$ and $p=0.67$, respectively).

In kidney recipients, CYP $3 A 5$ genotype was significantly associated with median tacrolimus dosing requirements, number of dose changes, and concentration/dose ratio (Table 3). CYP $3 A 5$ expressors needed higher tacrolimus doses [median 0.14 (range $0.07-0.21)$ vs. $0.09(0.01-0.35)$
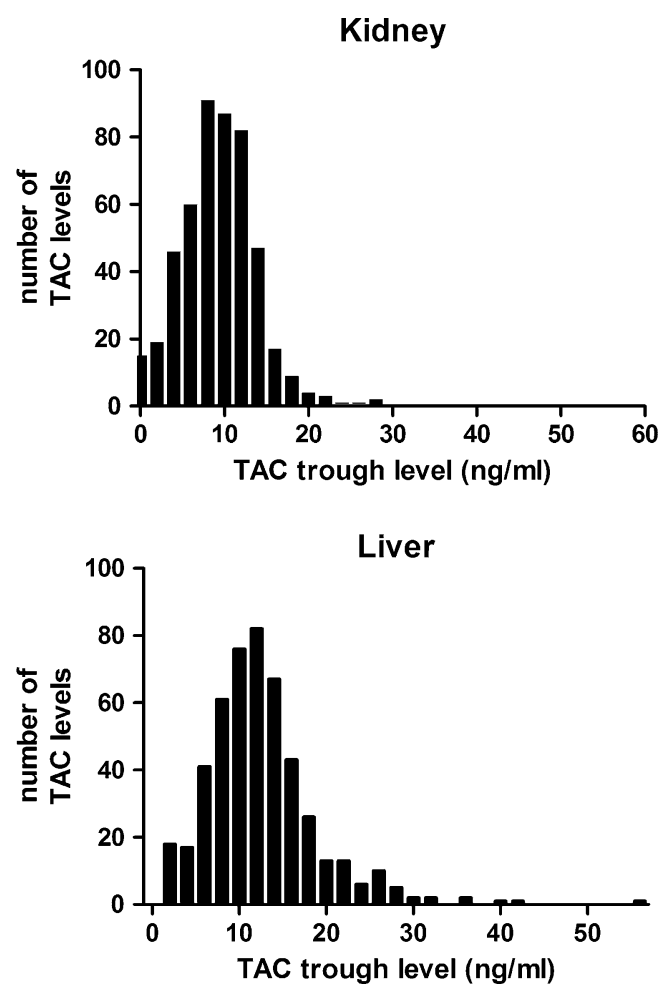

Fig. 1 Distribution of tacrolimus concentrations in relation to therapeutic target level by transplant type $\mathrm{mg} / \mathrm{kg} / 12 \mathrm{~h}, p=0.001]$ than nonexpressors (Fig. 2). CYP3A5 expressors also needed more upward dose changes, had lower median tacrolimus concentrations, and had lower $\mathrm{C} /$ $\mathrm{D}$ ratios (Table 3). In contrast, in liver recipients, we did not observe a relationship between recipient CYP3A5 and tacrolimus dosing requirements (Fig. 2), concentrations, or $\mathrm{C} / \mathrm{D}$ ratios (Table 3).

DNA for $A B C B 1$ genotyping was available for 45 kidney and 32 liver recipients. Genotype distribution is shown in Table 4. Genotype distribution was in Hardy-Weinberg equilibrium for all three polymorphisms tested in both transplant groups.

Upon inspection of the individual boxplots of dosing requirements vs. individual $\mathrm{ABCB} 1 \mathrm{SNPs}$, in liver, but not kidney, recipients homozygous for all three $\mathrm{T}$ alleles of polymorphisms, we noticed a trend towards higher dosing requirements. We then decided to analyze the relationship of the TT-TT-TT haplotype and found that liver recipients with this haplotype $(n=3)$ needed higher tacrolimus doses than the other patients $(n=29)$ [0.26 $(0.15-0.32)$ vs. 0.11 (0.01-0.25); $p=0.013]$.

Effect of age and PRISM on tacrolimus dosing and concentrations

Children younger than $<5$ years of age needed higher tacrolimus doses per kilogram of body weight than older children after both kidney and liver transplant (Fig. 3) [kidney: median 0.15 (range: $0.07-0.35)$ vs. $0.09(0.02-0.20) \mathrm{mg} / \mathrm{kg} /$ 12h, $p=0.046$, liver: $0.12(0.04-0.32)$ vs. $0.09(0.01-0.18)$ $\mathrm{mg} / \mathrm{kg} / 12 \mathrm{~h}, p=0.038]$.

The PRISM mortality scores were not correlated with tacrolimus dosing requirements, tacrolimus trough concentrations, or concentration/dose ratios in both transplant groups. Tacrolimus disposition did not differ between pediatric liver transplant recipients with $(n=7)$ or without $(n=35)$ initial graft liver failure. 
Table 3 Comparison of tacrolimus (tac) dosing characteristics by CYP3A5 genotype

\begin{tabular}{|c|c|c|c|c|c|c|}
\hline & \multicolumn{3}{|l|}{ Kidney recipients } & \multicolumn{3}{|l|}{ Liver recipients } \\
\hline & $\begin{array}{l}\text { CYP3A5 expressor } \\
(n=16) \\
\text { Median (range) }\end{array}$ & $\begin{array}{l}\text { CYP3A5 nonexpressor } \\
(n=28)\end{array}$ & $P$ & $\begin{array}{l}\text { CYP3A5 expressor } \\
(n=13) \\
\text { Median (range) }\end{array}$ & $\begin{array}{l}\text { CYP3A5 nonexpressor } \\
(n=22)\end{array}$ & $P$ \\
\hline Median tac trough level $(\mathrm{ng} / \mathrm{mL})$ & $7.3(4.7-11.1)$ & $10.3(2.8-15.5)$ & 0.01 & $10.8(8.1-14.8)$ & $11.0(5.0-15.4)$ & 0.80 \\
\hline Median tac dose $(\mathrm{mg} / \mathrm{kg})$ & $0.14(0.07-0.20)$ & $0.09(0.02-0.35)$ & 0.00 & $0.14(0.06-0.32)$ & $0.1(0-0.26)$ & 0.22 \\
\hline Conc/dose (ng/mL per mg/kg) & $50.1(25.5-92.5)$ & $103.1(31.3-280.3)$ & 0.00 & $75.8(38-136)$ & $105(24.7-1,939)$ & 0.24 \\
\hline Tac concentrations $<10 \mathrm{ng} / \mathrm{mL}(n)$ & $7(2-11)$ & $4(0-7)$ & 0.00 & $3(1-9)$ & $3(0-7)$ & 0.49 \\
\hline Tac concentrations $10-15 \mathrm{ng} / \mathrm{mL}(n)$ & $2(0-5)$ & $3(0-9)$ & 0.11 & $3(1-7)$ & $3(0-7)$ & 0.99 \\
\hline Tac concentrations $>15 \mathrm{ng} / \mathrm{mL}(n)$ & $0(0-2)$ & $0(0-3)$ & 0.05 & $1(0-5)$ & $2(0-5)$ & 0.43 \\
\hline Upward dose changes $(n)$ & $4(3-8)$ & $3(0-7)$ & 0.00 & $4(1-8)$ & $4(1-6)$ & 0.60 \\
\hline Downward dose changes $(n)$ & $1(0-4)$ & $1(0-4)$ & 0.56 & $3(0-5)$ & $3(0-5)$ & 0.85 \\
\hline
\end{tabular}

${ }^{*} P<0.05$ CYP3A5 expressors vs. nonexpressors

Interplay of covariates on tacrolimus dosing requirements

In kidney recipients, in multivariate analysis, both younger age and CYP $3 A 5$ expressor genotype were independently
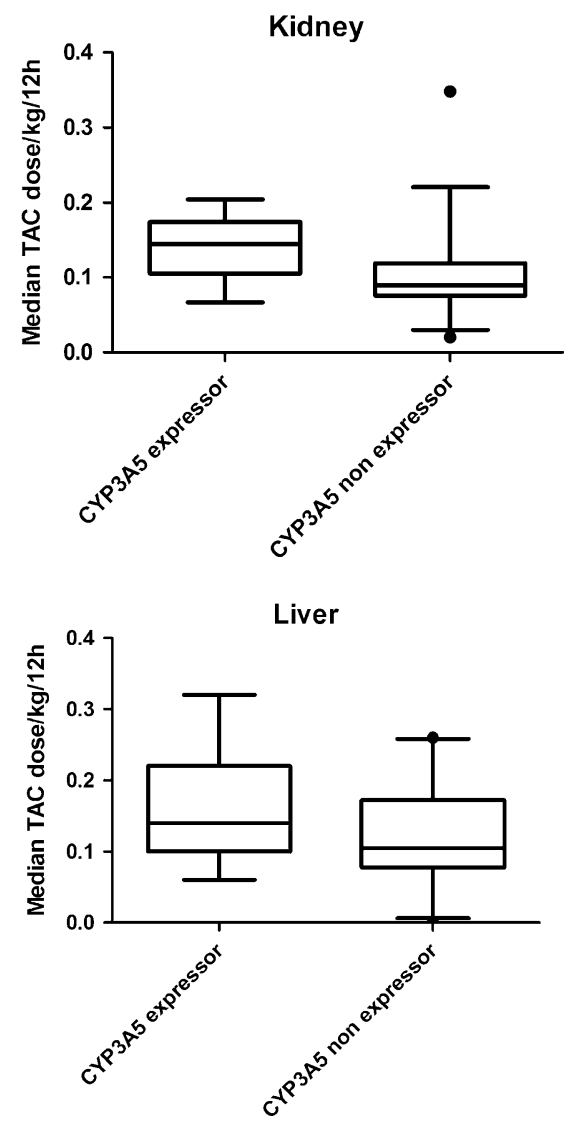

Fig. 2 Relationship between recipient CYP3A5 genotype and tacrolimus dosing requirements. Median (horizontal line), 5th and 95th percentiles (box), and range of tacrolimus dosing requirements by CYP3A5 expressor genotype of the subjects. The denominators for each group are indicated. Of the kidney recipients, CP3A5 expressors needed more tacrolimus than nonexpressors $(p<0.05)$ associated with higher tacrolimus dosing requirements $\left(r^{2}=0.362\right.$, corrected model $p=0.0001$, age F-value 4.6, $p=0.001$, CYP $3 A 5$ genotype F-value $1.3, p=0.005$ ).

Children older than 5 years of age who were CYP3A5 nonexpressors needed $0.09(0.02-0.15) \mathrm{mg} / \mathrm{kg} / 12 \mathrm{~h}$, whereas children younger than 5 years who were CYP3A5 expressors needed $0.19(0.18-0.2) \mathrm{mg} / \mathrm{kg} / 12 \mathrm{~h}$ tacrolimus. Patients younger than 5 who were nonexpressors as well as patients older than 5 who were expressors needed on average $0.13 \mathrm{mg} / \mathrm{kg} / 12 \mathrm{~h}$ (range $0.07-0.35 \mathrm{mg} / \mathrm{kg} / 12 \mathrm{~h}$ ).

\section{Discussion}

We aimed to study the interplay of age, genotype, and disease severity on tacrolimus disposition in the direct posttransplant period in 48 pediatric kidney and 42 pediatric liver transplant recipients. In a large proportion of our patients, tacrolimus concentrations were outside the therapeutic window in the first 14 days after transplant. Our results show that in pediatric kidney recipients, the patient's age and CYP3A5 genotype correlate with median tacrolimus dosing requirements and concentration/dose ratio in the first 14 days after transplant. In contrast, in pediatric liver recipients, age at transplant and $A B C B 1$ genotype seem to correlate with tacrolimus dosing requirements. We did not find a relation between disease severity, as determined by the PRISM score, and dosing requirements for either transplant group. Interestingly, in the kidney recipients, both younger age and CYP3A5 expressor genotype were independently associated with higher dosing requirements. This observation is important as it emphasizes the combined effect of genetic variation and ontogeny in relation to drug disposition. It has been shown in very young children that immaturity of drug metabolizing 
Table 4 Relationship of $A B C B 1$ genotype and tacrolimus (tac) dosing and disposition

\begin{tabular}{|c|c|c|c|c|c|c|c|c|c|}
\hline & & \multicolumn{8}{|c|}{ Transplant type } \\
\hline & & \multicolumn{4}{|l|}{ Kidney } & \multicolumn{4}{|l|}{ Liver } \\
\hline & & Median & Minimum & Maximum & Number & Median & Minimum & Maximum & Number \\
\hline \multicolumn{10}{|l|}{$\mathrm{ABCB} 1 \mathrm{C} 3435 \mathrm{~T}$} \\
\hline \multirow[t]{3}{*}{ Median tac dose (mg/kg) } & $\mathrm{CC}$ & 0.12 & 0.07 & 0.19 & 7 & 0.09 & 0.04 & 0.22 & 10 \\
\hline & $\mathrm{CT}$ & 0.09 & 0.02 & 0.20 & 16 & 0.11 & 0.00 & 0.25 & 15 \\
\hline & TT & 0.11 & 0.07 & 0.35 & 16 & 0.15 & 0.09 & 0.32 & 7 \\
\hline \multirow[t]{3}{*}{ Conc/dose (ng/ml per mg/kg) } & $\mathrm{CC}$ & 61.26 & 38.68 & 90.72 & 7 & 85.46 & 24.73 & 364.00 & 10 \\
\hline & $\mathrm{CT}$ & 101.16 & 25.48 & 280.31 & 16 & 96.95 & 33.20 & $1,939.80$ & 15 \\
\hline & TT & 50.07 & 31.34 & 156.40 & 16 & 72.14 & 41.13 & 209.89 & 7 \\
\hline \multirow[t]{3}{*}{ Median tac trough level $(\mathrm{ng} / \mathrm{mL})$} & $\mathrm{CC}$ & 9.10 & 4.70 & 11.05 & 7 & 11.18 & 5.00 & 14.40 & 10 \\
\hline & $\mathrm{CT}$ & 9.38 & 4.45 & 15.50 & 16 & 12.05 & 8.10 & 15.45 & 15 \\
\hline & TT & 8.43 & 2.80 & 13.05 & 16 & 10.40 & 8.10 & 15.10 & 7 \\
\hline \multicolumn{10}{|l|}{$\mathrm{ABCB} 1 \mathrm{C} 1236 \mathrm{~T}$} \\
\hline \multirow[t]{3}{*}{ Median tac dose $(\mathrm{mg} / \mathrm{kg})$} & $\mathrm{CC}$ & 0.11 & 0.02 & 0.19 & 11 & 0.11 & 0.07 & 0.22 & 11 \\
\hline & $\mathrm{CT}$ & 0.09 & 0.04 & 0.20 & 16 & 0.10 & 0.00 & 0.25 & 15 \\
\hline & TT & 0.11 & 0.07 & 0.35 & 12 & 0.15 & 0.06 & 0.32 & 6 \\
\hline \multirow[t]{3}{*}{ Conc/dose (ng/ml per mg/kg) } & $\mathrm{CC}$ & 0.10 & 38.68 & 280.31 & 11 & 0.11 & 24.73 & 190.95 & 11 \\
\hline & $\mathrm{CT}$ & 65.83 & 25.48 & 267.59 & 16 & 81.82 & 33.20 & $1,939.80$ & 15 \\
\hline & TT & 87.04 & 31.34 & 156.40 & 12 & 121.22 & 41.13 & 281.75 & 6 \\
\hline \multirow[t]{3}{*}{ Median tac trough level $(\mathrm{ng} / \mathrm{mL})$} & $\mathrm{CC}$ & 72.63 & 4.45 & 10.60 & 11 & 65.17 & 5.00 & 15.45 & 11 \\
\hline & $\mathrm{CT}$ & 77.40 & 2.80 & 15.50 & 16 & 87.25 & 8.25 & 15.10 & 15 \\
\hline & TT & 8.25 & 3.15 & 13.05 & 12 & 10.65 & 8.10 & 14.80 & 6 \\
\hline \multicolumn{10}{|l|}{ ABCB1G2677AT } \\
\hline \multirow[t]{5}{*}{ Median tac dose $(\mathrm{mg} / \mathrm{kg})$} & GG & 0.11 & 0.02 & 0.17 & 10 & 0.11 & 0.06 & 0.22 & 12 \\
\hline & GT & 0.09 & 0.04 & 0.20 & 17 & 0.10 & 0.00 & 0.25 & 13 \\
\hline & AT & 0.15 & 0.15 & 0.15 & 1 & 0.08 & 0.08 & 0.08 & 1 \\
\hline & GA & 0.19 & 0.18 & 0.19 & 2 & & & & \\
\hline & TT & 0.09 & 0.07 & 0.35 & 9 & 0.15 & 0.12 & 0.32 & 6 \\
\hline \multirow[t]{5}{*}{ Conc/dose (ng/ml per mg/kg) } & GG & 71.61 & 38.92 & 280.31 & 10 & 83.06 & 24.73 & 281.75 & 12 \\
\hline & GT & 90.72 & 25.48 & 267.59 & 17 & 136.14 & 33.20 & $1,939.80$ & 13 \\
\hline & AT & 67.77 & 67.77 & 67.77 & 1 & 133.77 & 133.77 & 133.77 & 1 \\
\hline & GA & 49.97 & 38.68 & 61.26 & 2 & & & & \\
\hline & TT & 94.77 & 31.34 & 156.40 & 9 & 65.17 & 41.13 & 121.22 & 6 \\
\hline \multirow[t]{5}{*}{ Median tac trough level $(\mathrm{ng} / \mathrm{mL})$} & GG & 8.48 & 4.45 & 10.60 & 10 & 10.33 & 5.00 & 13.60 & 12 \\
\hline & GT & 9.40 & 2.80 & 15.50 & 17 & 12.40 & 8.70 & 15.45 & 13 \\
\hline & AT & 10.80 & 10.80 & 10.80 & 1 & 8.25 & 8.25 & 8.25 & 1 \\
\hline & GA & 9.00 & 6.95 & 11.05 & 2 & & & & \\
\hline & TT & 8.90 & 3.15 & 13.05 & 9 & 10.60 & 8.10 & 14.80 & 6 \\
\hline
\end{tabular}

enzyme activity may obscure a genotype effect on drug disposition [22, 23]. In our study, patients were well above the neonatal age, therefore such an effect of ontogeny on gene-related variation in drug metabolism is less likely. Our results suggest that tacrolimus starting dosing guidelines in children should reflect both age and CYP3A5 genotype to reduce the time needed to reach therapeutic concentrations directly after transplant.

\section{Effect of genotype}

We were surprised to find a CYP3A5 genotype effect so early after transplant, as other covariates such as postsurgical inflammation, renal impairment, and changes in albumin and hematocrit concentrations could have obscured pharmacogenetic variation in tacrolimus exposure and dosing. In another study in pediatric kidney patients with 

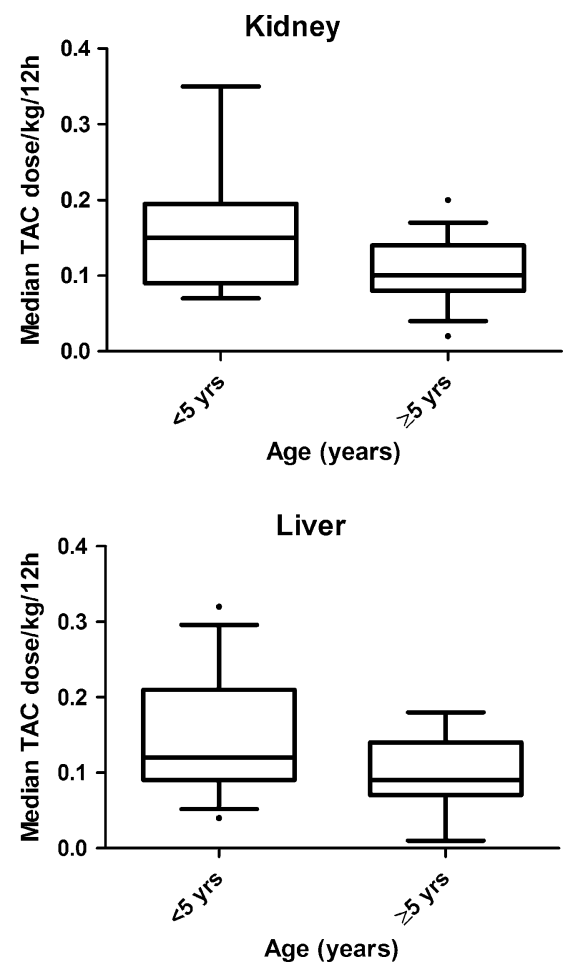

Fig. 3 Relationship between age and tacrolimus dosing requirements. Median (horizontal line), 5th and 95th percentiles (box), and range of tacrolimus dosing requirements by age of the subjects. Children less than 5 years of age needed more tacrolimus than older children in both transplant groups $(p<0.05)$

similar results [24], patients were studied slightly later after transplant. A single tacrolimus AUC was determined $20 \pm 12$ days after transplant. In contrast, tacrolimus dosing requirements were not different according to CYP $3 A 5$ genotype in the first 3 months after transplant in adolescent kidney transplant patients $(n=27)$, but this lack of association may be due to a lack of power due to the small sample size studied [10].

In pediatric liver recipients, we could not identify a relationship between recipient CYP $3 A 5$ genotype and tacrolimus dosing. The main reason for this lack of association is probably that variations in tacrolimus exposure are largely dependent on variation in hepatic metabolism and to a lesser extent on intestinal metabolism. Hence, donor CYP $3 A 5$ genotype may be more important to explain variability in tacrolimus dosing requirements than the recipient's genotype. Unfortunately, we were not able to collect donor DNA to test this assumption. Our hypothesis is confirmed by data from Fukudo et al., who estimated tacrolimus pharmacokinetics, using trough concentrations, in a cohort of 65 Japanese pediatric living-related liver recipients up to 50 days posttransplant [25]. Donor CYP3A5 genotype and recipient intestinal $A B C B 1$ expression but not recipient $C Y P 3 A 5$ genotype were associated with (recovery of) tacrolimus oral clearance immediately after transplant.
In liver recipients, we found higher dosing requirements in children with the TT-TT-TT haplotype. Our results are in contrast with other studies in adults and children [26]. Most studies did not find a relationship between tacrolimus dosing requirements or disposition and $A B C B 1$ genotype in liver transplant patients. In one study in 51 pediatric liver recipients, carriers of different variant alleles (e.g., G2677T/ A, C3425T, T-T-T haplotype) had higher C:D ratios (possibly reflecting lower clearance) $<3$ years after transplant [13]. This result seems to contrast our results. We found a trend (not significant) towards lower C:D ratios in patients with the TT-TT-TT haplotype. A possible explanation for these contradicting results is that, early after liver transplant, intestinal ABCB1 genotype in concert with intestinal CYP3A4 largely determines variation in tacrolimus disposition. Lower intestinal ABCB1 expression may result in more tacrolimus available for intestinal CYP3A4 metabolism, leading to lower systemic tacrolimus concentrations. Later after liver transplant, when the liver is fully regenerated, hepatic CYP3A5 may be more important. This is also supported by the lack of a relationship between $A B C B 1$ genotype and tacrolimus dosing requirements in our kidney recipients. This hypothesis stems from observations of a gender effect on the interaction between $A B C B 1$ 2677 genotype and CYP3A4 expression. [27, 28]. There is a significant interaction between this variant (2677 SNP) and a 6 bp deletion variant of NR1I2 (PXR) influencing CYP3A4 expression [28]. To our knowledge, none of the other adult or pediatric studies specifically studied a gender effect of $A B C B 1$ genotype. Our sample size was too small to study the effect of gender in relation to the $A B C B 1$ genotype and tacrolimus disposition. In addition, a gender effect on CYP3A4 expression is likely absent in prepubertal children. Another explanation for our finding of an ABCB1 effect in liver recipients may be a type I error due to the small size of our patient population. Only 3 (TT-TT-TT haplotypes) patients had the variant genotype in a total genotyped population of 32 patients. For this reason, we refrained from studying the interaction between $A B C B 1$ genotype and age in the liver patients.

The lack of a relationship between $A B C B 1$ polymorphisms and tacrolimus dosing and disposition in our pediatric kidney recipients is consistent with studies from adult and pediatric kidney recipients [24, 29, 30]. In contrast, others did find a relationship between $A B C B 1$ genotype and tacrolimus disposition in adult kidney recipients [31-33].

\section{Effect of age}

In both kidney and liver patients, children younger than 5 years of age needed more tacrolimus than older children. Our findings are in line with previous studies in pediatric 
liver and kidney recipients $[3,34,35,36,37]$. The reason why younger children need more tacrolimus than older children to reach the same tacrolimus target concentration is unknown. A wide range of age-related differences in drug disposition such as CYP3A4/5 metabolism and p-gp transport, volume of distribution, protein and erythrocyte binding, or renal function has been suggested [3]. To our knowledge, definite data are lacking on the impact of these possible mechanisms on tacrolimus disposition in children.

\section{Variation in concentrations}

In our patient population rigorous therapeutic drug monitoring was practiced, which is apparent from a median (range) of 9 (2-12) tacrolimus concentrations and 6 (1-11) dose changes in the first 14 days post-transplant. Despite this rigorous approach, less than $40 \%$ of all tacrolimus concentrations were within the predefined target range (10$15 \mathrm{ng} / \mathrm{ml}$ ). Also, $33 \%$ of kidney and $76 \%$ of liver recipients had at least one supratherapeutic tacrolimus concentration. For the kidney recipients, this percentage is lower than reported in a UK pediatric renal transplant cohort (65 vs. $33 \%$ in our patients) [38]. This difference may be explained by lower initial tacrolimus doses in our patients than in UK patients ( 0.1 vs. $0.15 \mathrm{mg} / \mathrm{kg}$ twice daily). In pediatric liver transplant patients, only $27 \%$ of all concentrations were in the therapeutic range, in a study comparing buccal versus nasogastric administered tacrolimus [39]. As has been illustrated in adults, even in the context of a clinical trial, achieving target drug concentrations is challenging, especially early after transplant [40]. It is to be expected that incorporation of known covariates, such as CYP $3 A 5$ genotype and age, in tacrolimus dosing regimens may reduce suboptimal tacrolimus dosing, as we found a relationship between genotype and nontherapeutic tacrolimus concentrations.

We hypothesized that part of the variation in tacrolimus disposition early after transplant may be due to variation in disease severity. We used a compound disease score (PRISM) to evaluate the role of disease severity on tacrolimus disposition but could not identify an effect. One limitation of the PRISM score is that it only takes into account the worst clinical and lab results within the first $24 \mathrm{~h}$ after ICU admission. Hence, variation in disease state after the first $24 \mathrm{~h}$ is not taken into account. In addition, as this is a compounded score, variations only in liver or kidney graft function that may impact tacrolimus metabolism may be missed using this score. We did, however, not find a difference in tacrolimus disposition when we compared patients with and without initial graft failure. In adult liver recipients, a more sensitive test of liver function, the LiMAx test, could predict tacrolimus trough levels [41].
Limitations

A limitation of our study is that tacrolimus dosing information was collected retrospectively from hospital databases. This may contribute to unexplained variation in dosing requirements, for example, when a child vomits and the drug needs to be re-administered. Also, it was not reported clearly how the drug was administered, by mouth, gastric, or duodenal tube, nor was it clear if the drug was given as suspension or as tablets. Furthermore, it was not known if the patient was receiving oral feeds or parenteral nutrition, which may also have contributed to unexplained variation in oral absorption. Previous studies have shown that different administration modes and fasting may also contribute to variation in oral tacrolimus pharmacokinetics $[2,42]$. Further studies need to show if tacrolimus oral granules formulation could improve early GI absorption of the drug in children with consequently more stable exposure. Another limitation is that we did not include deceased patients, as it was not possible to collect DNA. Deceased patients may have suffered more frequently from transplant rejection and serious adverse events, resulting in death. It would have been interesting to include these patients, to determine if they were frequent outliers with respect to dosing requirements in relation to their CYP $3 A 5$ genotype. In addition, the lack of impact of PRISM score on tacrolimus disposition in this cohort may have been due to this lack of inclusion of deceased patients, as this might have contributed to a larger variation in PRISM scores.

Based on our results, tacrolimus dosing in pediatric kidney transplant patients could be based on genotype and age. Starting doses of tacrolimus as high as $0.2 \mathrm{mg} / \mathrm{kg} / 12 \mathrm{~h}$ could be considered in young ( $<5$ years of age) CYP3A5 expressors (double the frequently used start dose). For the other agegenotype combinations, the effect was less pronounced ( 0.13 $\mathrm{mg} / \mathrm{kg} / 12 \mathrm{~h}$ for older, CYP3A5 expressors and younger, nonexpressors vs. $0.9 \mathrm{mg} / \mathrm{kg} / 12 \mathrm{~h}$ for older, nonexpressors).

In adults, a recent genotype-based dosing trial showed indeed that genotype-based dosing resulted in a shorter time to reach therapeutic levels ( 8 vs. 25 days in $75 \%$ of patients). However, no difference in rejection rate was found [43]. Additionally, adult CYP $3 \mathrm{~A} 5 * 3$ expressors seem at higher risk to develop tacrolimus-induced nephrotoxicity, despite similar or lower tacrolimus exposure [44]. Hence, at this time genotype-based dosing in children might need to be restricted to trials evaluating its short- and long-term effect.

\section{Conclusion}

In conclusion, our results indicate that recipient CYP $3 A 5$ genotype and age independently contribute to the variation 
in tacrolimus dosing requirements and successful achievement of therapeutic tacrolimus concentrations in pediatric kidney recipients. In this population, individualized dosing schedules, incorporating both age and recipient CYP $3 A 5$ genotype may be needed to optimize tacrolimus dosing. In pediatric liver recipients, our results suggest that recipient $A B C B 1$ genotype and age, but not CYP3A5 genotype contribute to tacrolimus dosing requirements. Further studies should focus on the design and validation of genotype (recipient and donor) and age-based dosing regimens of tacrolimus, as well as on the effect of individualized dosing on outcome, i.e., transplant rejection rates and adverse events, such as nephrotoxicity.

Acknowledgments The support from Sick Kids Transplant Center patients and their parents and staff, including nurses, physicians, and administrators, was invaluable for conducting this study. This research was supported by grants from the ter MeulenFund (Royal Dutch Academy of Sciences, SNW) and the Research Institute of the Hospital for Sick Children (Research Training Competition, SNW/IN).

Open Access This article is distributed under the terms of the Creative Commons Attribution Noncommercial License which permits any noncommercial use, distribution, and reproduction in any medium, provided the original author(s) and source are credited.

\section{References}

1. Masuda S, Inui K (2006) An up-date review on individualized dosage adjustment of calcineurin inhibitors in organ transplant patients. Pharmacol Ther 112(1):184-198

2. Staatz CE, Tett SE (2004) Clinical pharmacokinetics and pharmacodynamics of tacrolimus in solid organ transplantation. Clin Pharmacokinet 43(10):623-653

3. Naesens M, Salvatierra O, Li L, Kambham N, Concepcion W, Sarwal M (2008) Maturation of dose-corrected tacrolimus predose trough levels in pediatric kidney allograft recipients. Transplantation 85(8):1139-1145

4. Zheng H, Webber S, Zeevi A, Schuetz E, Zhang J, Bowman P, Boyle G, Law Y, Miller S, Lamba J, Burckart GJ (2003) Tacrolimus dosing in pediatric heart transplant patients is related to CYP3A5 and MDR 1 gene polymorphisms. Am J Transplant 3(4):477-483

5. Yu S, Wu L, Jin J, Yan S, Jiang G, Xie H, Zheng S (2006) Influence of CYP3A5 gene polymorphisms of donor rather than recipient to tacrolimus individual dose requirement in liver transplantation. Transplantation 81(1):46-51

6. Quteineh L, Verstuyft C, Furlan V, Durrbach A, Letierce A, Ferlicot S, Taburet AM, Charpentier B, Becquemont L (2008) Influence of CYP3A5 genetic polymorphism on tacrolimus daily dose requirements and acute rejection in renal graft recipients. Basic Clin Pharmacol Toxicol 103(6):546-552

7. MacPhee IA, Fredericks S, Tai T, Syrris P, Carter ND, Johnston A, Goldberg L, Holt DW (2004) The influence of pharmacogenetics on the time to achieve target tacrolimus concentrations after kidney transplantation. Am J Transplant 4(6):914-919

8. Kuypers DR, de Jonge H, Naesens M, Lerut E, Verbeke K, Vanrenterghem Y (2007) CYP3A5 and CYP3A4 but not MDR1 single-nucleotide polymorphisms determine long-term tacrolimus disposition and drug-related nephrotoxicity in renal recipients. Clin Pharmacol Ther 82(6):711-725
9. Hesselink DA, van Schaik RH, van der Heiden IP, van der Werf M, Gregoor PJ, Lindemans J, Weimar W, van Gelder T (2003) Genetic polymorphisms of the CYP3A4, CYP3A5, and MDR-1 genes and pharmacokinetics of the calcineurin inhibitors cyclosporine and tacrolimus. Clin Pharmacol Ther 74(3):245-254

10. Ferraresso M, Tirelli A, Ghio L, Grillo P, Martina V, Torresani E, Edefonti A (2007) Influence of the CYP3A5 genotype on tacrolimus pharmacokinetics and pharmacodynamics in young kidney transplant recipients. Pediatr Transplant 11(3):296-300

11. Chen JS, Li LS, Cheng DR, Ji SM, Sun QQ, Cheng Z, Wen JQ, Sha GZ, Liu ZH (2009) Effect of CYP3A5 genotype on renal allograft recipients treated with tacrolimus. Transplant Proc 41 (5): 1557-1561

12. Quteineh L, Verstuyft C (2010) Pharmacogenetics in immunosuppressants: impact on dose requirement of calcineurin inhibitors in renal and liver pediatric transplant recipients. Curr Opin Organ Transplant 15 (5): 601-607

13. Hawwa AF, McKiernan PJ, Shields M, Millership JS, Collier PS, McElnay JC (2009) Influence of ABCB1 polymorphisms and haplotypes on tacrolimus nephrotoxicity and dosage requirements in children with liver transplant. Br J Clin Pharmacol 68(3):413-421

14. Satoh $S$, Kagaya $H$, Saito $M$, Inoue $T$, Miura $M$, Inoue $K$, Numakura K, Tsuchiya N, Tada H, Suzuki T, Habuchi T (2008) Lack of tacrolimus circadian pharmacokinetics and CYP3A5 pharmacogenetics in the early and maintenance stages in Japanese renal transplant recipients. Br J Clin Pharmacol 66(2):207-214

15. Haas CE, Kaufman DC, Jones CE, Burstein AH, Reiss W (2003) Cytochrome P450 3A4 activity after surgical stress. Crit Care Med 31(5):1338-1346

16. Nanashima A, Pillay P, Verran DJ, Painter D, Nakasuji M, Crawford M, Shi L, Ross AG (2002) Analysis of initial poor graft function after orthotopic liver transplantation: experience of an Australian single liver transplantation center. Transplant Proc 34(4):1231-1235

17. Pollack MM, Ruttimann UE, Getson PR (1988) Pediatric risk of mortality (PRISM) score. Crit Care Med 16(11):1110-1116

18. Volosov A, Napoli KL, Soldin SJ (2001) Simultaneous simple and fast quantification of three major immunosuppressants by liquid chromatography-tandem mass-spectrometry. Clin Biochem 34(4):285-290

19. Aarnoudse AJ, Dieleman JP, Visser LE, Arp PP, van der Heiden IP, van Schaik RH, Molokhia M, Hofman A, Uitterlinden AG, Stricker BH (2008) Common ATP-binding cassette B1 variants are associated with increased digoxin serum concentration. Pharmacogenet Genomics 18(4):299-305

20. Lepper ER, Baker SD, Permenter M, Ries N, van Schaik RH, Schenk PW, Price DK, Ahn D, Smith NF, Cusatis G, Ingersoll RG, Bates SE, Mathijssen RH, Verweij J, Figg WD, Sparreboom A (2005) Effect of common CYP3A4 and CYP3A5 variants on the pharmacokinetics of the cytochrome P450 3A phenotyping probe midazolam in cancer patients. Clin Cancer Res 11(20):7398-7404

21. Becker ML, Visser LE, van Schaik RH, Hofman A, Uitterlinden AG, Stricker BH (2009) Common genetic variation in the ABCB1 gene is associated with the cholesterol-lowering effect of simvastatin in males. Pharmacogenomics 10(11):1743-1751

22. Leeder JS (2001) Pharmacogenetics and pharmacogenomics. Pediatr Clin North Am 48(3):765-781

23. Blake MJ, Gaedigk A, Pearce RE, Bomgaars LR, Christensen ML, Stowe C, James LP, Wilson JT, Kearns GL, Leeder JS (2007) Ontogeny of dextromethorphan $\mathrm{O}$ - and $\mathrm{N}$-demethylation in the first year of life. Clin Pharmacol Ther 81(4):510-516

24. Zhao W, Elie V, Roussey G, Brochard K, Niaudet P, Leroy V, Loirat C, Cochat P, Cloarec S, Andre JL, Garaix F, Bensman A, Fakhoury M, Jacqz-Aigrain E (2009) Population pharmacokinetics and pharmacogenetics of tacrolimus in de novo pediatric kidney transplant recipients. Clin Pharmacol Ther 86(6):609-618

25. Fukudo M, Yano I, Masuda S, Goto M, Uesugi M, Katsura T, Ogura Y, Oike F, Takada Y, Egawa H, Uemoto S, Inui K (2006) 
Population pharmacokinetic and pharmacogenomic analysis of tacrolimus in pediatric living-donor liver transplant recipients. Clin Pharmacol Ther 80(4):331-345

26. Hawwa AF, McElnay JC (2011) Impact of ATP-binding cassette, subfamily $\mathrm{B}$, member 1 pharmacogenetics on tacrolimusassociated nephrotoxicity and dosage requirements in paediatric patients with liver transplant. Expert Opin Drug Saf 10:9-22

27. Hosohata K, Masuda S, Yonezawa A, Katsura T, Oike F, Ogura Y, Takada Y, Egawa H, Uemoto S, Inui K (2009) MDR1 haplotypes conferring an increased expression of intestinal CYP3A4 rather than MDR1 in female living-donor liver transplant patients. Pharm Res 26(7):1590-1595

28. Lamba J, Strom S, Venkataramanan R, Thummel KE, Lin YS, Liu W, Cheng C, Lamba V, Watkins PB, Schuetz E (2006) MDR1 genotype is associated with hepatic cytochrome P450 3A4 basal and induction phenotype. Clin Pharmacol Ther 79(4):325-338

29. Haufroid V, Mourad M, Van Kerckhove V, Wawrzyniak J, De Meyer M, Eddour DC, Malaise J, Lison D, Squifflet JP, Wallemacq P (2004) The effect of CYP3A5 and MDR1 (ABCB1) polymorphisms on cyclosporine and tacrolimus dose requirements and trough blood levels in stable renal transplant patients. Pharmacogenetics 14 (3): $147-154$

30. Tada H, Tsuchiya N, Satoh S, Kagaya H, Li Z, Sato K, Miura M, Suzuki T, Kato T, Habuchi T (2005) Impact of CYP3A5 and MDR1 (ABCB1) C3435T polymorphisms on the pharmacokinetics of tacrolimus in renal transplant recipients. Transplant Proc 37(4):1730 1732

31. Akbas SH, Bilgen T, Keser I, Tuncer M, Yucetin L, Tosun O, Gultekin M, Luleci G (2006) The effect of MDR1 (ABCB1) polymorphism on the pharmacokinetic of tacrolimus in Turkish renal transplant recipients. Transplant Proc 38(5):1290-1292

32. Anglicheau D, Verstuyft C, Laurent-Puig P, Becquemont L, Schlageter $\mathrm{MH}$, Cassinat B, Beaune P, Legendre C, Thervet E (2003) Association of the multidrug resistance-1 gene singlenucleotide polymorphisms with the tacrolimus dose requirements in renal transplant recipients. J Am Soc Nephrol 14(7):1889-1896

33. Li D, Gui R, Li J, Huang Z, Nie X (2006) Tacrolimus dosing in Chinese renal transplant patients is related to MDR1 gene C3435T polymorphisms. Transplant Proc 38(9):2850-2852

34. Kim JS, Aviles DH, Silverstein DM, Leblanc PL, Matti Vehaskari $\mathrm{V}$ (2005) Effect of age, ethnicity, and glucocorticoid use on tacrolimus pharmacokinetics in pediatric renal transplant patients. Pediatr Transplant 9(2):162-169
35. Montini G, Ujka F, Varagnolo C, Ghio L, Ginevri F, Murer L, Thafam BS, Carasi C, Zacchello G, Plebani M (2006) The pharmacokinetics and immunosuppressive response of tacrolimus in paediatric renal transplant recipients. Pediatr Nephrol 21(5):719-724

36. Yasuhara M, Hashida T, Toraguchi M, Hashimoto Y, Kimura M, Inui K, Hori R, Inomata Y, Tanaka K, Yamaoka Y (1995) Pharmacokinetics and pharmacodynamics of FK 506 in pediatric patients receiving living-related donor liver transplantations. Transpl proc 27(1):1108-1110

37. Wallemacq PE, Furlan V, Moller A, Schafer A, Stadler P, Firdaous I, Taburet AM, Reding R, Clement De Clety S, De Ville De Goyet J, Sokal E, Lykavieris L, Van Leeuw V, Bernard O, Otte JB, Undre NA (1998) Pharmacokinetics of tacrolimus (FK506) in paediatric liver transplant recipients. Eur J Drug Metab Pharmacokinet 23(3):367-370

38. Kausman JY, Patel B, Marks SD (2008) Standard dosing of tacrolimus leads to overexposure in pediatric renal transplantation recipients. Pediatr Transplant 12(3):329-335

39. Goorhuis JF, Scheenstra R, Peeters PM, Albers MJ (2006) Buccal vs. nasogastric tube administration of tacrolimus after pediatric liver transplantation. Pediatr Transplant 10(1):74-77

40. Ekberg H, Mamelok RD, Pearson TC, Vincenti F, Tedesco-Silva H, Daloze P (2009) The challenge of achieving target drug concentrations in clinical trials: experience from the Symphony study. Transplantation 87(9):1360-1366

41. Lock JF, Malinowski M, Schwabauer E, Martus P, Pratschke J, Seehofer D, Puhl G, Neuhaus P, Stockmann M (2011) Initial liver graft function is a reliable predictor of tacrolimus trough levels during the first post-transplant week. Clin Transplant 25:436-443

42. Reding R, Sokal E, Paul K, Janssen M, Evrard V, Wilmotte L, Chardot C, Otte JB, Wallemacq P (2002) Efficacy and pharmacokinetics of tacrolimus oral suspension in pediatric liver transplant recipients. Pediatr Transplant 6(2):124-126

43. Thervet E, Loriot MA, Barbier S, Buchler M, Ficheux M, Choukroun G, Toupance O, Touchard G, Alberti C, Le Pogamp P, Moulin B, Le Meur Y, Heng AE, Subra JF, Beaune P, Legendre C (2010) Optimization of initial tacrolimus dose using pharmacogenetic testing. Clin Pharmacol Ther 87:721-726

44. Kuypers DR, Naesens M, de Jonge H, Lerut E, Verbeke K, Vanrenterghem Y (2010) Tacrolimus dose requirements and CYP3A5 genotype and the development of calcineurin inhibitorassociated nephrotoxicity in renal allograft recipients. Ther Drug Monit 32 (4): 394-404 